\title{
A proposal for energy efficient design: an IFC based design decision system and its application
}

\author{
E. Turkyılmaz \\ Istanbul Kültür University, Turkey
}

\begin{abstract}
Today, a large part of the total energy consumed in buildings is used to provide adequate indoor air quality and indoor lighting. The dirt and noise of urban environments encourage keeping buildings closed tight, with a resultant reliance on mechanical systems. Despite tightening the building envelope to decrease energy consumption, the building itself becomes more dependent on mechanical systems and monitors to assure adequate heat, ventilation and air-conditioning. The need, amount and the timing of energy efficient air conditioning are the subjects of studies, which include how to provide efficient air conditioning to control indoor air quality. Within this context, the aim of the research is to develop a design decision system to provide sufficient and consistent knowledge on air-conditioning for the design process. Today, there are only a few systems serving the same aim with a very limited capacity. These systems are not designed to be either cost-effective or industrial applicable. Air-conditioning and air circulation analysis of spaces are made by CFD (Computer Fluid Dynamics) software. In order to use air-conditioning and air circulation analysis in design process efficiently, CFD analysis software and BIM (Building Information Modelling) software should work together.

Three steps are followed to develop the proposed system. First, what the results of air circulation analysis used by architects is composed of. Second, an interface is designed to define air circulation analysis in BIM software. Third, additional properties set to Industry Foundation Classes (IFCs) standard to keep analysis data on BIM model is prepared. A computer laboratory and a conference room are chosen to test the developed system. The evaluation of preliminary test results are shown that the developed system produces easily understandable graphic analysis for architects. While using the proposed system, air-
\end{abstract}


conditioning is no longer a very general characteristic of a design process but it is a real design feature forming the overall design process.

Keywords: energy efficient design, BIM, IFC, CFD.

\section{Introduction}

In the $21^{\text {st }}$ century, energy requirements due to increasing population and industrialization century have not been covered on the limited resources of the world. The energy consumption of buildings is comprehensively affected by many factors such as building size, thermal aspect of the building envelope, performance and operation mode of building service systems, temperature, and so on, some of which (e.g. temperature) are always chancing [1].

The building sector is responsible for $40 \%$ of the total energy consumption in the EU. Half of the energy consumed by buildings is due to the use of heating, ventilation and air conditioning systems [2]. A recent EU directive defines the ambitious goal for reducing energy consumption and greenhouse gas emissions and requires all buildings constructed in 2020 or later to be "nearly zero-energy buildings" [3]. Future projections indicate that in 2030, buildings will be responsible for $35.6 \%$ of the primary energy use in the world and continue to maintain its importance. As a contribution to the "Kyoto Protocol" the European Union outlined the objective to reduce energy consumption by $20 \%$ up to 2020 . As buildings account for almost $40 \%$ of the total energy usage in Europe, the European Commission undertakes much effort to reduce the energy consumption of buildings [4].

A large part of the total energy consumed in buildings in the world is used to provide adequate indoor air quality and indoor lighting. The dirt and noise of urban environments encourage keeping buildings closed tight, with a resultant reliance of mechanical systems. This, in turn, contributes to the exterior noise level and intensifies both energy consumption and the heat island effect. Despite tightening the building envelope to decrease energy consumption, the building itself become more dependent on mechanical systems and monitors to assure adequate ventilation. The need, amount and the timing of energy adequate air ventilation are the subjects of countless studies, which include how to provide efficient air ventilation to control indoor air quality most effectively.

Within this context, the aim of the research is to develop a design decision system to provide sufficient and consistent knowledge on air-conditioning for the design process. Today, there are only a few systems serving the same aim with very limited capacities. These systems are not designed to be either cost-effective or applicable to industry. Air-conditioning and air circulation analysis of spaces are made by CFD (Computer Fluid Dynamics) software. In order to use airconditioning and air circulation analysis in design process efficiently, CFD analysis software and BIM (Building Information Modelling) software should work together. 


\section{The relationship between energy efficient building design and building information modelling}

To achieve a significant improvement in energy efficient building design, one key is using the appropriate building modelling methods, considering the relevant engineering interdependencies, especially in the early phases, to support the design process and the design experts involved. Energy efficient building design requires considering the geometric and visual properties of the design as well as the physical, technical and economic engineering interdependencies that determine the building's performance [3].

The traditional design, construction and operation stages of buildings have been affected by the consideration of sustainability, especially the use of energy. Several approaches and technologies have been developed to ensure that targets for energy savings and $\mathrm{CO}_{2}$ emissions can be achieved by more sustainable and more efficient use of energy. Among the used technologies is the use of BIM (Building Information Modelling) to model energy usage, thermal flows, lighting patterns and other sustainability measures [5].

Building Information Modelling is a building design and documentation method. The usage of BIM in the architecture, engineering and construction (ACE) sector has been increasing rapidly. The concept of BIM contains the formation and the usage of the design, construction and management knowledge of buildings. The computational model of BIM forms an environment serving the various disciplines of design process to work together.

Information sharing should be a starting point when it comes to applying information technology to architectural design, construction and use. Information sharing requires a software environment in which computer programs can exchange data automatically regardless of software and data location. Towards this goal, the IAI proposed a standard that specifies object representations for AEC projects. Today, IFCs (Industry Foundation Classes) is the fundamental file type of the ACE industry.

IFC is an object-oriented data information model. It contains all kinds of information of ACE projects. These data are located in IFC data files. IFC data file creates a neutral file type to share and to change project information efficiently. IFC has released four versions since 1994. The leader software of ACE industry (Revit, ArchiCAD, Allplan etc.) work compatibly with IFC.

IFC includes object specifications, or classes, and provides a useful structure for data sharing among applications. For instance, an IFC door is not just a simple collection of lines and geometric primitives recognized as a door; it is an intelligent object door which has a door's attributes linked to a geometrical definition [6].

\section{The relationship between Industry Foundation Classes and Computer Fluid Dynamics}

Computer Fluid Analysis (CFD) has been introduced to the ACE and HVAC industry for decades. Its effectiveness in assisting the architects and engineers in 
the design process of the indoor and outdoor environment of buildings has been acknowledged. Most of the currently available CFD simulation tools are designed for generic purpose. Several of them are suitable and widely used in the building industry [7].

In recent years, CFD has become a very powerful and popular tool in building simulation. CFD has been widely used to model indoor and outdoor airflow, heat transfer and contaminant transport. The applications of CFD in building design include site planning, natural ventilation studies, HVAC system designs or pollution dispersion and control. CFD is particularly suited for modelling indoor conditions in naturally ventilated spaces, which are difficult to predict using other types of simulation tools [2].

Although there has been a lot of research focusing on CFD modelling, the reliability of the results remains a significant concern regarding CFD simulations. While CFD models can produce visually appealing results, accuracy is often a key issue. In order to produce credible and verifiable results, the CFD model should be created using verified software and experimental data to support model validation. At the same time, the simulation of the indoor environment requires the expertise to handle complex boundary conditions [2].

Reliability and robustness of CFD simulations are critical in situations when physical testing is too expensive or infeasible. There is a demand for accurate CFD models of indoor environments at the design and the operation stage of the building life cycle. At the same time, true models of the built environments may lead to research in new directions [2].

Although an IFC file type contains every data, the formation of these data are not compatible with CFD software. It is required to convert the data of IFC to the data of CFD software. Air-conditioning calculations are realized by CFD software by using the data of IFC model. Once the calculation made, it should be important to give feedback to the design process from the results of air conditioning calculations. In this way, air-conditioning has not been thought of anymore as a very general characteristic of the design process. It will be a real design feature forming the overall design process. At the same time, architects can have sufficient knowledge about this issue and use their knowledge from the early design phase to the final product phase.

Finite element analysis packages such as ANSYS FLUENT can be used to carry out complex CFD analyses to understand the implications of the winds and other physical factors on the design as well as its surroundings [8]. ANSYS FLUENT, a general purpose CFD software, does not support working compatibly with BIM software. ANSYS FLUENT uses AIRPAK, another software developed by ANSYS to solve air-conditioning problems. AIRPAK forms data files for ANSYS FLUENT and ANSYS FLUENT presents some graphics of results. However, to form data files with AIRPAK is not easy and it is required to draw the whole model with AIRPAK again. The resulting graphics of analysis are also made by AIRPAK. ANSYS FLUENT is used only for the presentation of graphics. 


\section{Case study}

\subsection{Spatial description}

The 3D geometry of the room (Figure 1) was created based on the technical drawings. Previous research has shown that a high level of detail in the CFD model would not influence the overall air circulation inside the room but significantly increase grid and computational cost. Additionally, when the focus is on the global air circulation of a ventilated space, a simple geometry of a human manikin is sufficient. The elements of the room, windows, chairs, tables etc., were simplified [2].

\subsection{CFD model}

The system was proposed using the commercial CFD software ANSYS FLUENT. ANSYS FLUENT was used to obtain information on the performance of air conditioning and air circulation system of a computer laboratory. Similar analyses can also be conducted to check the effectiveness of natural ventilation.

The effects of computers and workers on the air circulation in a computer laboratory were analysed. In the first stage, the simulation of airflow through the duct was carried out and then the outlet conditions for the duct were saved and provided as the profile data for the inlet condition(s) of the room.

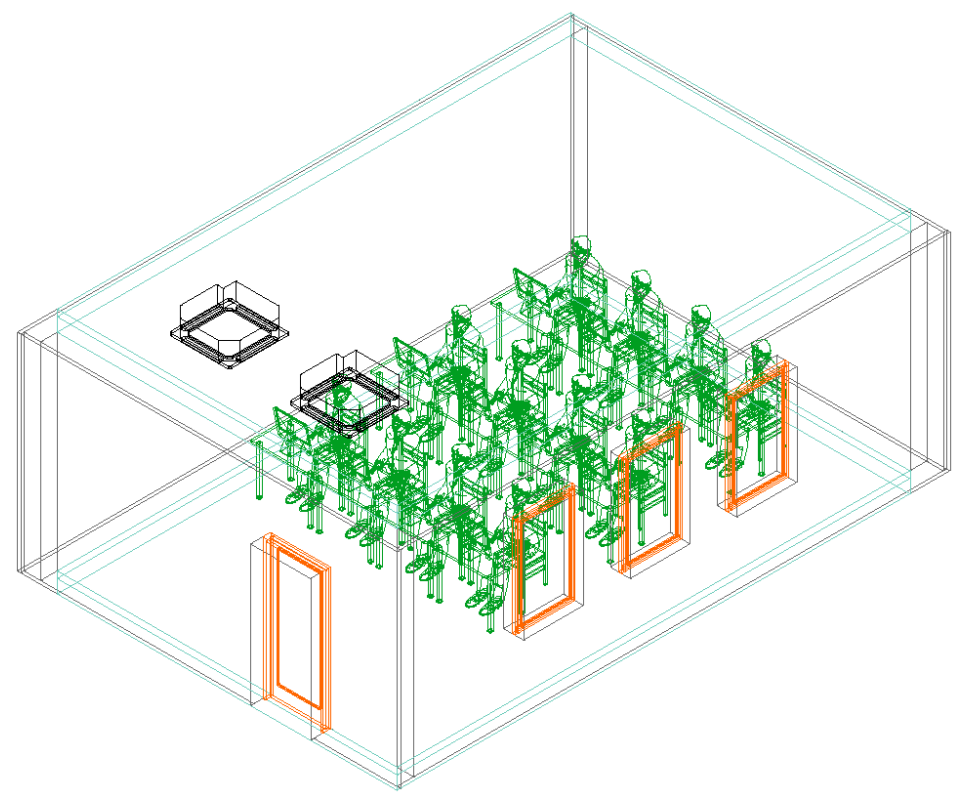

Figure 1: $\quad$ Architectural model of computer laboratory. 


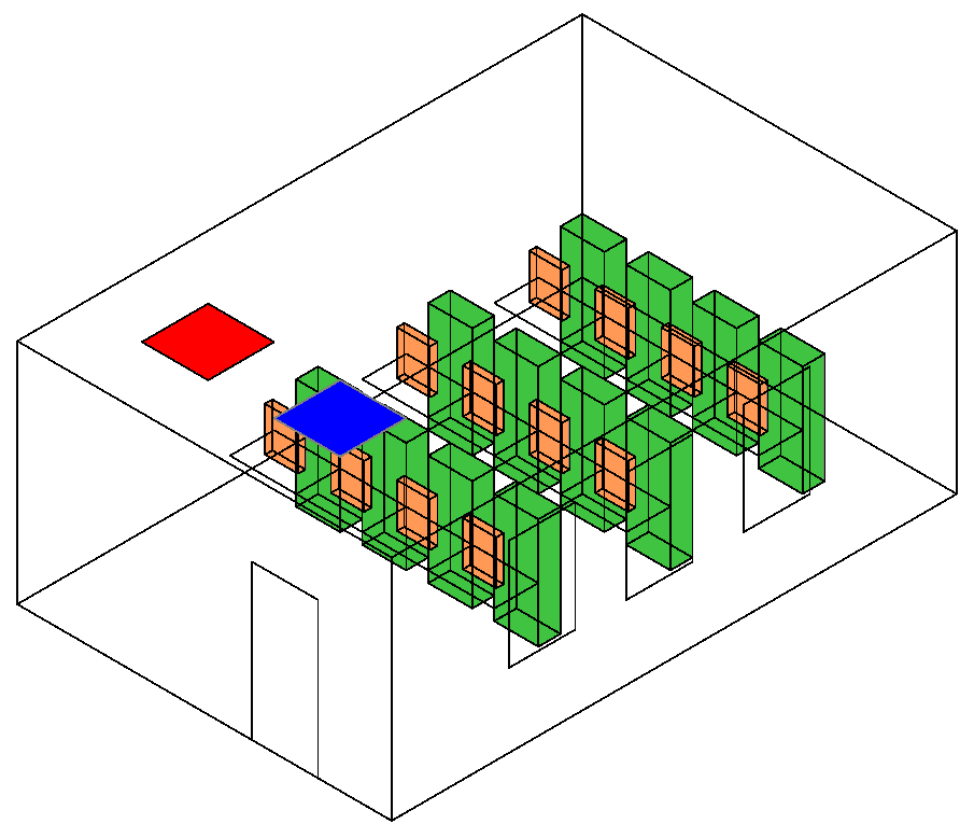

Figure 2: $\quad$ CFD model of computer laboratory.

The accuracy of the CFD simulation strongly depends on the model boundary conditions specified by the modeller. It is important to stimulate the environment as close as possible to the real conditions (Figure 2). However, detailed information about the boundary conditions is not always easily available for the particular space. Gathering this information may be time consuming. At the same time, some parameters' input to the model would more or less influence the results. It is up to a modeller to decide the accuracy of the model input parameters, which is difficult especially for inexperienced CFD modellers [2].

While using the proposed system, it is possible to create any surfaces at any location, not just as the boundaries. As a first step, the density of a different location can be observed; streamlines from each vents can be created. As a second step, the streamlines can be animated and different surfaces can be created.

\section{Conclusion}

Computer based methods are used in an impressive and exciting way in various fields of architecture such as advanced geometry and computer-aided production methods. New tools make it possible to design and actually build forms that would not be possible without the use on computers. Incorporating building information modelling into the design process utilizes the full potential of computational methods in architecture. 
Architectural design is a knowledge-based activity. A variety of knowledge is required; gathering it consistently in order to create a design product. Architects use their own knowledge from the early design phase to the final product phase. However, some knowledge used by architects to make design decisions is very general and achieved solutions are not enough.

Air-conditioning in architecture has not been considered adequately because of the very general knowledge of architects. Mechanical engineers or HVAC engineers try to convert an air-conditioning system to architectural design. While using contemporary systems, controlling the sufficiency and suitability of the airconditioning system has not been realized. It is also not possible to give feedback to the design process about this system.

Well planned air circulation strategies in the built environments can provide healthy and comfortable indoor conditions, while contributing to a significant reduction in the energy consumed by buildings. Hence, accurate and reliable CFD models of naturally ventilated indoor spaces are necessary to correctly design and operate built environments. However, creating accurate CFD models, those truly represent real environments, requires a high level of expertise and modeller's time. Furthermore, it is widely reported in the CFD community that the results of the CFD simulations depend highly on the model parameters input by the user.

Three steps are followed to develop the proposed system. First, what the results of air circulation analysis used by architects is composed of. Second, an interface is designed to define air circulation analysis in BIM software. Third, additional property sets to IFC standard to keep analysis data on the BIM model is prepared. A computer laboratory and a conference room are chosen to test the developed system. The developed system produces easily understandable graphic analysis for architects. While using the proposed system, air-conditioning is no longer a very general characteristic of the design process but it is a real design feature forming the overall design process.

\section{References}

[1] Ma, Z. \& Zhao, Y., Model of next generation energy-efficient design software for buildings. Tsinghua Science and Technology, 13(1), 48/67, pp. 298-304, 2008.

[2] Hajdukiewicz M. \& Geron, M. \& Keane, M.M., Formal calibration methodology for CFD models of naturally ventilated indoor environments. Building and Environment, 59, pp. 290-302, 2013.

[3] Geyer, P., Systems modeling for sustainable building design. Advanced Engineering Informatics, 26, pp. 656-668, 2012.

[4] Gökçe, H.U. \& Gökçe, K.U., Holistic system architecture for energy efficient building operation. Sustainable Cities and Society, 6, pp. 77-84, 2013.

[5] Motawa, I. \& Carter, K., Sustainable BIM-based evaluation of buildings. Procedia-Social and Behavorial Sciences, 74, pp. 419-428, 2013. 
[6] Vanlande, R., Nicolle, C., Cruz, C., IFC and building lifecycle management. Automation in Construction, 18, pp. 70-78, 2008.

[7] Zhang, R., Zhang, Y., Poh Lam, K., Archer, D.H., A prototype mesh generation tool for CFD simulations in architecture domain. Building and Environment, 45, pp. 2253-2262, 2010.

[8] Yazıcı, G. \& Erkan Yazıcı, Y., The use of finite element analysis applications in architectural education. International Journal on New Trends in Education and Their Implications, 3(4), pp. 148-155, 2012.

[9] Schlueter, A. \& Thesseling, F., Building information model based energy/exergy performance assessment in early design stages. Automation in Construction, 18, 153-163, 2009. 